\title{
LAS REDES SOCIALES EN INTERNET
}

\section{SOCIAL NETWORKS IN THE INTERNET}

\author{
Antonia Cascales Martínez; antonia.cascales@um.es \\ Universidad de Murcia \\ José Julio Real García; real.julio@gmail.com \\ Universidad Autónoma de Madrid \\ Benedicto Marcos Benito; bmarcos.b@gmail.com \\ IES Miguel de Cervantes (Madrid)
}

\section{RESUMEN}

Son muchas las utilidades de los wikis pero quizá uno de lo usos mas significativos de las redes en la educación son las múltiples posibilidades que ofertan para desarrollar propuestas de colaboración entre docentes que comparten un mismo proyecto de trabajo, en este caso la animación lectora. En esta misma línea, encontramos multitud de herramientas y aplicaciones de Internet que nos proporcionan diferentes ventajas como son espacios compartidos, toma de decisiones comunes, asignación de tareas y responsabilidades, votaciones, gestiones de grupo, entre otros. El objetivo de este artículo es exponer una experiencia de trabajo colaborativo mediante la animación a la lectura y mostrar las características principales de las aplicaciones para el trabajo colaborativo utilizando una red social Ning para los docentes, como complemento y ampliación al uso de las wikis, para el alumnado.

PALABRAS CLAVE Wikis, redes sociales, trabajo colaborativo, animación a la lectura.

\begin{abstract}
Many are the uses of wikis, but perhaps their most important application is the wide range of possibilities that they offer to develop shared projects among teachers, in this case, reading stimulation in the classroom. In this line, we can find many tools and Internet applications which provide us with a number of advantages such as shared spaces, a framework for decision making and responsibilities and tasks assignment, and group management. The main aim of this article is to present a collaborative work experience by means of reading stimulation and to show the key application of wikis, in particular by the use of Ning social network by both teachers and students.
\end{abstract}

KEY WORDS Wikis, social networks, collaborative work, reading stimulation in the classroom. 


\section{INTRODUCCIÓN}

La figura de "red de relaciones sociales» en determinadas estructuras sociales, se ha utilizado en multitud de escritos sociológicos y antropológicos a lo largo de la historia de estas disciplinas. Sin embargo, esta utilización tenía un sentido simplemente metafórico y muy diferente del concepto de red social como una serie de vínculos entre un conjunto definido de actores sociales.

Las características de estos vínculos como un todo tienen la propiedad de proporcionar interpretaciones de la conducta social de los actores implicados en la red. En la segunda mitad de la década de los cincuenta, algunos antropólogos británicos ${ }^{1}$ realizaron estudios de campo en los que usaron con rigor el concepto de red social, dando a éste un valor heurístico. Pero ha sido durante la pasada década cuando el análisis de redes ha cobrado mayor interés dentro de disciplinas como la sociología o la antropología, iniciándose, en numerosas universidades del mundo anglosajón, líneas de investigación coincidentes con las más diversas aplicaciones del análisis de redes.

Una red en la teoría de los grafos es un conjunto de relaciones en el cual las líneas que conectan los diferentes puntos tienen un valor concreto, sea éste numérico o no. Esta posibilidad de cuantificar un vínculo es una de las cualidades que mayor interés puede tener para la sociología. El concepto de red social introducido por Barnes ${ }^{2}$ en su estudio sobre los parroquianos de las islas noruegas concuerda aproximadamente con la definición y propiedades que ha enunciado la teoría de los grafos. Aunque esta teoría matemática no es restrictiva a redes finitas, sin embargo en sociología, por cuestiones pragmáticas, normalmente es necesario trabajar con un conjunto identificable de actores (personas, grupos, etc.) y las relaciones que existen entre ellos.

Con Internet las redes sociales adquieren una nueva dimensión y se está viviendo un importante auge, que en poco tiempo han provocado que el volumen de participación de los internautas se haya multiplicado exponencialmente. En Europa 282,7 millones de internautas mayores de 15 años son usuarios de de redes sociales lo que representa el 74, 6 por ciento de este segmento de población. En España el porcentaje es similar el 73,7 por ciento, ${ }^{3}$ dentro de los cuales 5,64 millones de usuarios son usuarios de Tuenti.

Otro dato relevante, según el estudio de la Asociación para la investigación de medios de comunicación (AIMC) ${ }^{4}$, cerca de la mitad de los internautas (un 46\%) contribuye con contenidos propios a la web. Un 32,9 por ciento ha "subido" alguna foto en el último mes, mientras que un 20 por ciento lo ha hecho con textos y algo menos de la mitad, un 9,6 por ciento, ha realizado lo propio con videos.

Una red social en Internet es una comunidad de usuarios registrados en un portal web que comparten información, interactúan entre ellos mediante mensajes y cuentan con otras

\footnotetext{
Véanse los trabajos de J. A. BARNES, «Class and committees in a Norwegian Island Parish», Human Relations, vol. 7, 1954, pp. 39-58, y de E. BOTT, Family and social networks, Nueva York, Free Press, 1971 (2.a ed.), donde se usa por primera vez el concepto de red de forma sistemática y analítica.

Este antropólogo fue el primero en definir el concepto de red en un sentido analítico.

Su definición era la siguiente: “Cada persona está, por así decirlo, en contacto con cierto número de otras personas, algunas de las cuales están en contacto entre sí y otras no. Creo conveniente denominar red a un campo social de este tipo. La imagen que tengo es la de una red de puntos los cuales algunos están unidos por líneas. Los puntos de esta imagen unas veces serán personas y otras grupos, y las líneas indicarían quiénes interactúan entre sí.»

http://www.comscore.com/press/release.asp?press=2733

http://www.aimc.es/aimc.php?izq=audiencia.swf\&op=dos\&pag_html=si\&dch=03internet/32.html
} 
formas de colaboración. En una red de este tipo, conocida como comunidad virtual, se forman grupos de amigos por afinidad. Cada usuario registrado puede mantener una lista de contactos considerados como amigos, los cuales deben de estar registrados en el portal. Un usuario puede enviar una invitación a un destinatario de correo, si no es usuario del portal, se le pide que se registre, y si acepta seguramente otros usuarios le pedirán que sea su amigo o incluso el invitará a otros.

Además de poder compartir información por medio de una Red social, a veces nos encontramos ante la necesidad de un espacio colaborativo en el que cada miembro de esa comunidad pueda depositar sus aportaciones personales.

Para esto el Wiki es el medio más idóneo. Es un espacio que además de compartir esa información, el alumno puede construir su propio conocimiento. Una herramienta que permite construir la información y el conocimiento entre iguales y por medio de ella los alumnos pueden realizar trabajos de forma colaborativa por medio de Webquest, de Cazas de Tesoros, pueden escribir el periódico escolar del centro, realizar un trabajo de investigación, etc.

También podemos utilizarla entre profesionales como una excelente herramienta que propicie un modelo de formación, que fomente la creación de comunidades profesionales y redes sociales y que permitan el trabajo cooperativo entre iguales.

\section{REDES SOCIALES EN INTERNET}

Según el ISFTIC: "Las redes sociales son, sin lugar a dudas, uno de los desarrollos más innovadores de la Web 2.0. Concebidas con el propósito de interconectar usuarios que comparten aficiones, amistades, ideas, fotografías, vídeos y elementos multimedia de todo tipo, han crecido hasta la hipertrofia, engullendo una buena parte del tráfico de información en la Red. Aplicaciones como YouTube, MySpace, Flickr, Orkut o Facebook, además de ocupar el ranking absoluto de los lugares más visitados de Internet, constituyen un auténtico fenómeno de masas, del que podemos extraer numerosas aplicaciones educativas".

Y según Wikipedia: "El origen del software de las redes sociales parte de la teoría de los seis grados de separación, según la cual todas las personas que habitan el planeta están conectadas por medio de no más de seis de ellas ${ }^{5}$. Investigaciones en Canadá y Estados Unidos afirman esta teoría. Ellos comprobaron en sus estudios que fuera de Internet, las personas estudiadas tenían como término medio no más de seis lazos íntimos de relación fuera de la familia y, al mismo tiempo, muchísimos lazos débiles que mantenían aisladamente. Se plantea que en los últimos diez años, esta tendencia de relaciones se ha mantenido como media en el comportamiento de las personas. De hecho, existe una patente en Estados Unidos conocida como six degrees patent, junto con otras muchas invenciones que protegen la tecnología para automatizar la creación de redes y las aplicaciones relacionadas con estas".

La teoría fue inicialmente propuesta en 1929 por el escritor húngaro Frigyes Karinthy en una corta historia llamada Chains. El concepto está basado en la idea que el número de conocidos crece exponencialmente con el número de enlaces en la cadena, y sólo un pequeño número de enlaces son necesarios para que el conjunto de conocidos se convierta en la población humana entera. 


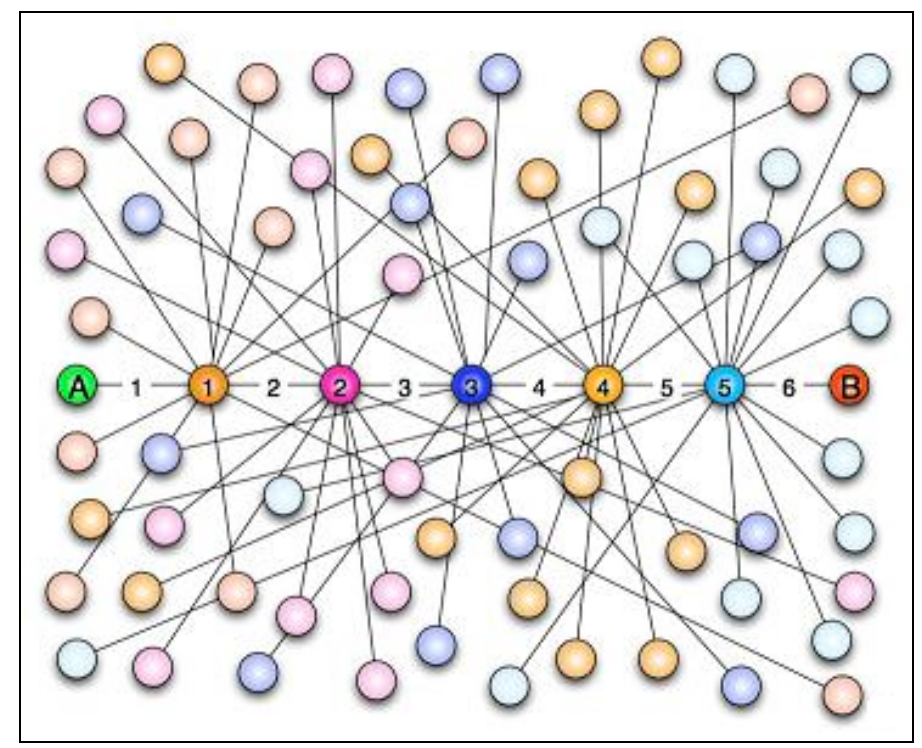

Six degrees of separation

Siguiendo con esta teoría 6 , "cada persona conoce de media, entre amigos, familiares y compañeros de trabajo o escuela, a unas 100 personas. Si cada uno de esos amigos o conocidos cercanos se relaciona con otras 100 personas, cualquier individuo puede pasar un mensaje a 10.000 personas más tan solo pidiendo a un amigo que pase el mensaje a sus amigos. Estos 10.000 individuos serían contactos de segundo nivel, que un individuo no conoce pero que puede conocer fácilmente pidiendo a sus amigos y familiares que se los presenten, y a los que se suele recurrir para ocupar un puesto de trabajo o realizar una compra".

"Cuando preguntamos a alguien, por ejemplo, si conoce una secretaria interesada en trabajar estamos tirando de estas redes sociales informales que hacen funcionar nuestra sociedad. Este argumento supone que los 100 amigos de cada persona no son amigos comunes. En la práctica, esto significa que el número de contactos de segundo nivel será sustancialmente menor a 10.000 debido a que es muy usual tener amigos comunes en las redes sociales. Si esos 10.000 conocen a otros 100 , la red ya se ampliaría a 1.000 .000 de personas conectadas en un tercer nivel, a 100.000.000 en un cuarto nivel, a 10.000.000.000 en un quinto nivel y a 1.000.000.000.000 en un sexto nivel. En seis pasos, y con las tecnologías disponibles, se podría enviar un mensaje a cualquier lugar individuo del planeta. Evidentemente cuanto más pasos haya que dar, más lejana será la conexión entre dos individuos y más difícil la comunicación. Internet, sin embargo, ha eliminado algunas de esas barreras creando verdaderas redes sociales mundiales, especialmente en segmento concreto de profesionales, artistas, etc".

\footnotetext{
$6 \quad$ En la década de los 50, Ithiel de Sola Pool (MIT) y Manfred Kochen (IBM) se propusieron demostrar la teoría matemáticamente. Aunque eran capaces de enunciar la cuestión "dado un conjunto de $\mathrm{N}$ personas, ¿cual es la probabilidad de que cada miembro de estos $\mathrm{N}$ estén conectados con otro miembro vía k1, k2, k3,..., kn enlaces?", después de veinte años todavía eran incapaces de resolver el problema a su propia satisfacción.
} 
Y por último "En términos de análisis de redes sociales, siempre se dice que una red es una especie de conjunto de individuos que en forma colectiva o individual interactúan entre ellos por un objetivo común. Entonces, el análisis de redes sociales es una herramienta que permite definir (según sea el caso) las diferentes interacciones que pueden ocurrir entre diferentes tipos de individuos. Para esto, el análisis se apoya en fuentes de datos (relacionados con el tema en cuestión) de carácter más cualitativo que cuantitativo, lo que permite, a partir de la aplicación de un grupo de técnicas determinadas, ordenar de cierto modo las interacciones existentes entre dichos individuos, de modo que puedan representarse sus relaciones en forma de grafo o red".

\section{FILOSOFÍA DE LAS REDES SOCIALES}

La filosofía de las redes sociales se basa en el principio de comunidad abierta y no jerarquizada, que vincula a los usuarios mediante un tema o actividad común y una plataforma web (software social) que permite a los usuarios operar de manera sencilla e intuitiva en lo que se conoce como 'ámbito de las 3Cs' (content, construction and colaboration):

- Contenidos libres de derechos de autoría y generados gracias al trabajo individual (blogs, posts en los foros) o colaborativo (wikis, multiblogs) de los miembros de la red. La variedad y riqueza de contenidos, constituye un elemento clave a la hora de valorar la actividad y relevancia de una red social.

- Construcción.- El propósito principal de las redes on-line es construir una trama consistente de intereses, usuarios y productos. Para ello el sitio deberá ofrecer un conjunto de herramientas y servicios que satisfagan las necesidades de la comunidad y sean a la vez potentes e intuitivos. Los más comunes son: Editores de texto, gestores de usuarios y enlaces, sistemas de carga y descarga de ficheros, dispositivos de mensajería, tablones de anuncios, foros, utilidades para la sindicación y votación de contenidos, aplicaciones de trabajo en línea, etc.

- Colaboración. La web social, es básicamente, un instrumento de colaboración multiusuario. Los elementos de interactividad toman como referente los productos multimedia publicados en cualquier plataforma que permita comentar, modificar, valorar, descargar o vincular una nube ubicua de objetos con posición permanente en la red (permalink ${ }^{7}$ ). Los instrumentos de interactividad son tremendamente sencillos $y$ transparentes, facilitando que los internautas actúen de manera personalizada sobre aquellos contenidos que centran su interés.

\section{LA RED SOCIAL NING}

La red social Ning ${ }^{8}$ fue creada en 2005 por M. Andreessen y G. Bianchini, es la más utilizada para entornos educativos. Según aparece en el ítem de Wikipedia esta palabra significa paz en chino. La plataforma está construida en Java y el servicio corre en PHP. Una de las dife-

\footnotetext{
Un 'permalink' es un enlace permanente que contiene una URL única para cada 'contendor de información'. De este modo, resulta mucho más sencillo acceder y vincular los artículos de un blog, los comentarios de un foro o las imágenes, vídeos y animaciones colocadas en sitios como Flickr, YouTube o SlideShare.

http://www.ning.com/
} 
rencias significativas con respecto a Facebook y a MySpace es que cualquier usuario puede construir sus propias redes sociales y, por supuesto, agregarse a las ya formalizadas. Esta plataforma centrada en comunidades de intereses específicos tiene en estos momentos 240.000 redes sociales creadas y va en camino de convertirse en una red viral exitosa. Cuando alguien crea "su" red social ya cuenta con las siguientes herramientas: blog, foro, gestión de usuarios, grupos, posibilidad de generar eventos, añadir fotos y vídeos e integrar widgets de todo tipo. Gestiona bastante bien los aspectos de privacidad y visibilidad de la web.

Ning es un servicio online que permite a los usuarios crear su propia red social y unirse y participar en otras redes. También permite que los creadores de redes determinen la apariencia y funcionalidad de los sitios, así como decidir si serán públicos o privados. La mayor parte de las redes incluyen características tales como fotos o vídeos, listas de los miembros de la red y eventos, grupos dentro de la red y herramientas de comunicación tales como foros o blogs.

Para establecer una red social no se requieren habilidades técnicas y no hay límites en el número de redes a las que se puede unir un usuario. Ning ofrece redes gratuitas que están sostenidas por publicidad, o bien los usuarios pueden pagan pro servicios premium que la eliminan y permite que aquello elijan las URLS de las redes que no están en el dominio de Ning.

Una red social es una estructura de personas en la que los nodos representan individuos y éstos establecen distintas formas de relaciones entre ellos. La red social más utilizada para entornos educativos o eduredes es la Ning, que significa paz en chino.

Como ejemplo de utilización se puede consultar el siguiente vídeo:

Redes sociales en tres minutos: htahtp://www.youtube.com/watch?v=LsfMoBVjs_Q

\section{ANIMACIÓN A LA LECTURA A TRAVÉS DE UNA RED SOCIAL}

Se creado una red denominada "Baúl de Recursos y Materiales" a la que se accede desde la dirección http://enredamos.ning.com/

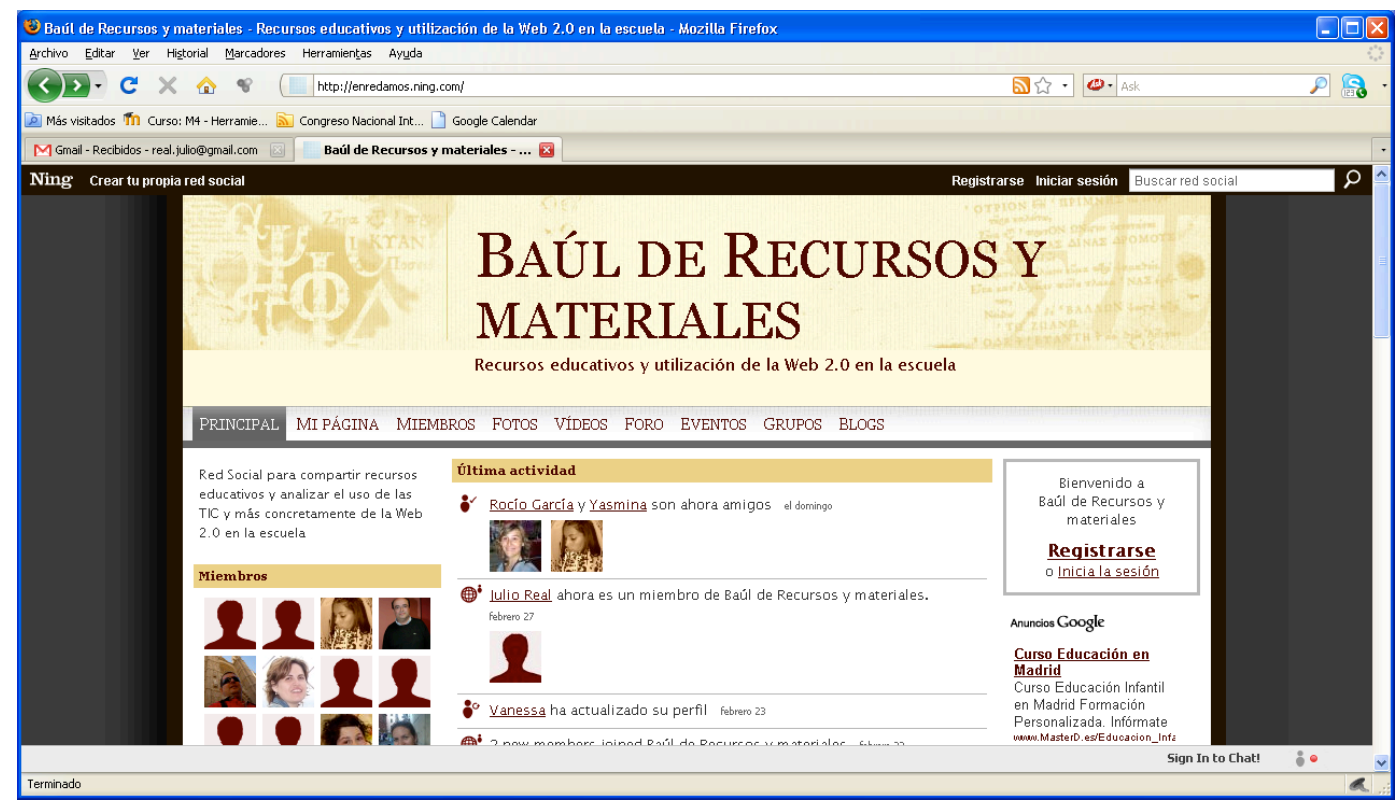


Hemos creado esta Red Social como una zona de trabajo exclusivamente para los profesores del proyecto.

En ella cada miembro expondrá sus dudas, los trabajos que realiza con la clase, los enlaces interesantes que encuentre referidos al tema, fotografías, vídeos, enlaces con los diferentes Blog creados en el centro y comentarios que se hayan introducido en los mismos, etc. y por supuesto un enlace con el Wiki, centro del presente trabajo.

Esta Red en principio nace para uso exclusivo de los profesores del Centro pero la idea es que se incorporen a la misma otros profesionales de diferentes centros educativos y que sea como una plataforma de ideas, de intercambio y de opiniones de diferentes temas educativos. Por ello serán los miembros actuales los que irán invitando a otros compañeros para aumentar el número de miembros integrantes en nuestra Red.

Como hemos dicho antes, desde esta red creada, podemos acceder de forma directa a nuestro wiki que dejamos alojado en la dirección http://desampanautas.wetpaint.com/ y que será la zona de trabajo para los alumnos.

En é los alumnos irán depositando sus aportaciones, sus comentarios, sus imágenes, vídeos, etc. En dicho Wiki podemos apreciar que tenemos creada una página para cada uno de los diferentes ciclos educativos del colegio y así de esta manera facilitar el trabajo a los alumnos a la hora de realizar sus aportaciones.

Volviendo al tema de la Red Social, para acceder a ella, lo primero que debes hacer es REGISTRARTE, accediendo a Mi Página y allí rellenar el Registro:

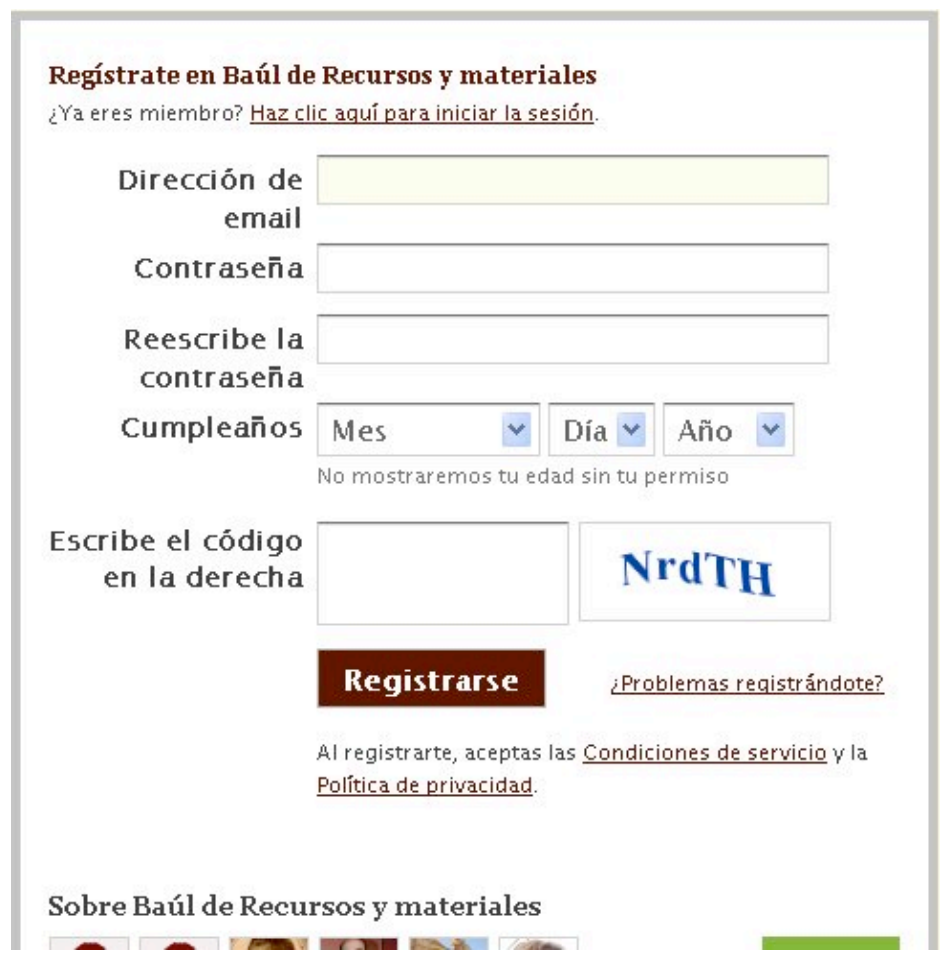

En el futuro, cuando quieras volver a hacer uso de la Red Social solamente necesitarás recordar el e-mail y la contraseña que has introducido la primera vez.

Lo primero que debes hacer es entrar en Mi página y modificar la información que te pide 


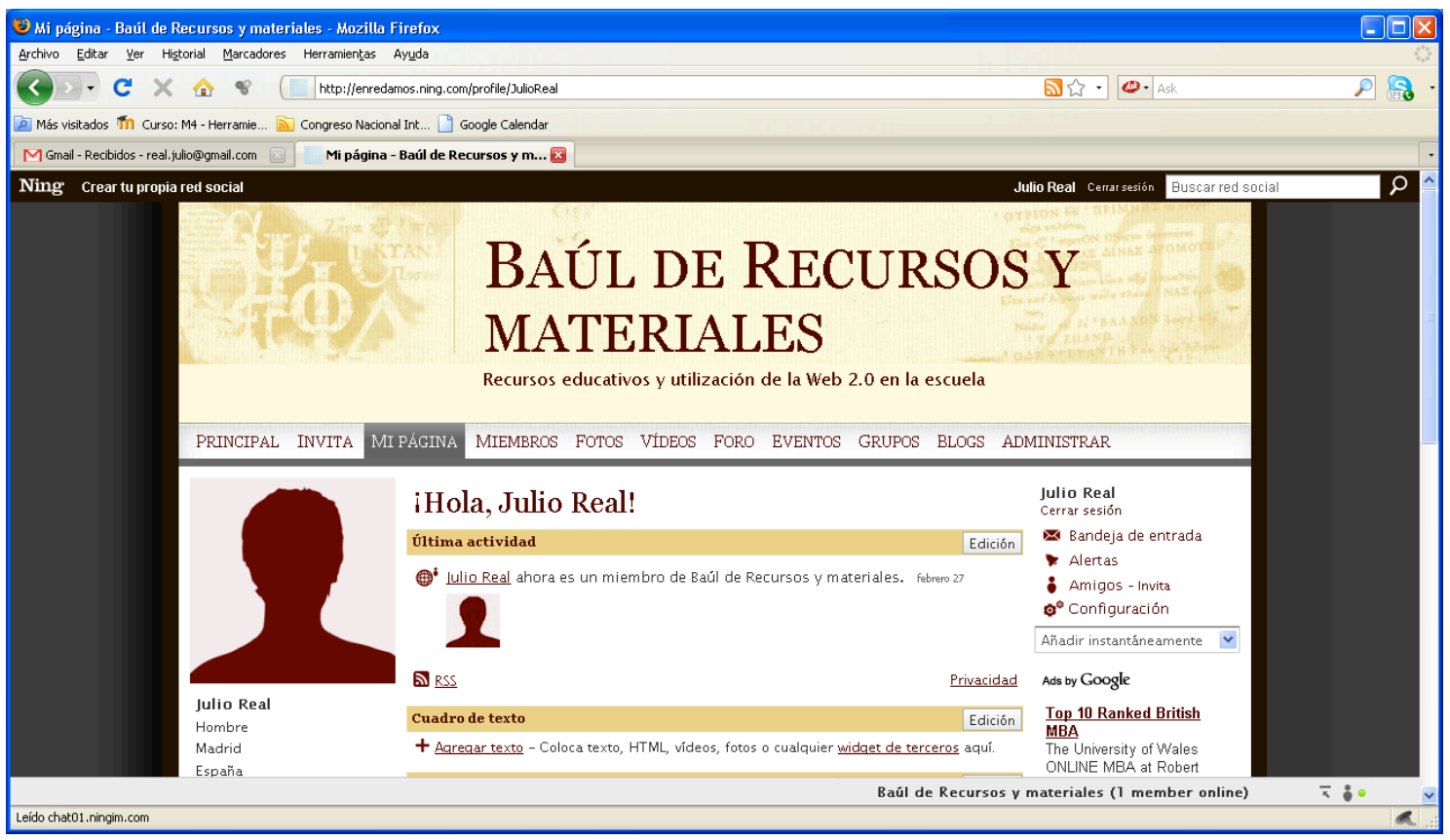

para completar tu perfil y poner tu foto, estos datos serán útiles para los miembros de la comunidad. Puedes incluir intereses personales, profesionales, recomendaciones, blogs, webs interesantes... Esta información también la podrás editar más adelante.

\section{PARA MOVERTE EN LA RED SOCIAL}

- En la página Principal encontrarás todas las novedades y la portada de la comunidad. Es dónde se informa de las actualizaciones y tienes una visión global de la red.

\section{PRINCIPAL INVITA MI PÁgINA MIEMBROS FOTOS VÍdEOS FORO EVENTOS GRUPOS BLOGS ADMINISTRAR}

- En el apartado Mi página encontrarás tu información. Además, puedes añadir cajas de texto (que admiten lenguaje html y embeds) para ampliar tu perfil con las informaciones que desees mostrar al grupo. Cada uno tiene un perfil y también podrás visualizarlo.

PRINCIPAL INVITA MI PÁgINA Miembros Fotos Vídeos Foro EVENTOS GRUPOS BLOGS AdMINISTRAR

MUY IMPORTANTE: Haciendo "clic" en EDITAR "información de mi perfil" se accede a un menú que permite, entre otras cosas, controlar los e-mail que recibiremos. Si no queremos recibir tantos correos, podemos desactivar algunas opciones.

- Podrás ver todos los integrantes en la pestaña Miembros y te puedes hacer amigo/a virtual y/o real si te lo ofrecen o lo pides. 
- En las pestañas Fotos y Vídeos encontrarás todos los que los participantes han ido colgando o referenciando en estos dos soportes digitales.

PRINCIPAL INVITA MI PÁgINA MIEMBRos FOTOS VídeOS FORO EVENTOS GRUPOS BLOGS ADMINISTRAR

- En el apartado de Blogs puedes escribir tus posts o tus comentarios a los artículos que ya están hechos. Las aportaciones son individuales.

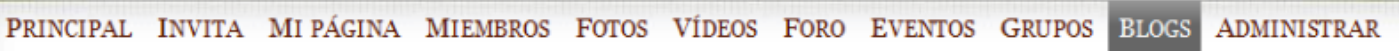

- En el apartado de Grupos tienes la posibilidad de realizar diferentes grupos de trabajo teniendo en cuenta los intereses de los miembros de la Red

PRINCIPAL INVITA MI PÁgINA Miembros Fotos Vídeos Foro EVENTOS GRUPOS Blogs ADMinistraR

-En el apartado Foro encuentras los debates abiertos a la participación de toda la comunidad. Y donde podemos exponer nuestras dudas de cómo funciona todo.

- También se pueden dejar Comentarios a los perfiles personales, a las fotografías, los vídeos, etc.

$\mathrm{Y}$, si es necesario, en la parte superior, tenemos acceso a un servicio de Correo interno, que a diferencia de las otras participaciones, es privado y no público.

- A la derecha encontrarás el acceso a Configuración desde donde puede modificar el perfil, la apariencia, la privacidad y las notificaciones que deseas recibir o no a la dirección de correo con la que te has registrado.

$$
0^{\circ} \text { Configuración }
$$

\section{EL WIKI}

Un wiki, o una wiki, es un sitio web cuyas páginas web pueden ser editadas por diferentes usuarios de forma muy sencilla. Estos usuarios pueden crear, modificar o borrar un mismo texto que comparten.

A fin de cuentas es como un gran tablón de anuncios donde cualquiera puede hacer sus aportaciones, incluso borrar o modificar las aportadas por otros. 
Es una buena herramienta de trabajo en grupo y es extraordinario el hecho de permitirnos el poder compartir información, escribir, anotar, corregir...etc.

La esencia de un wiki es la colaboración entre varias personas para generar información. Desde un punto de vista educativo, es un importante esfuerzo comunitario en el que es posible la colaboración, y ofrece a los estudiantes una zona de libre acceso y los profesores pueden incluso tratar de que los estudiantes, como parte de sus tareas, escriban sus propias colaboraciones en dicha zona.

En general, los wikis pueden ser configurados para ser espacios web públicos o espacios de trabajos privados, y poder desarrollar proyectos o coordinar tareas entre grupos de trabajos dispersos. Estos grupos están interconectados y se puede asignar a uno o a varos usuarios el rol de "moderador wiki".

Si nunca se ha experimentado con este tipo de aplicaciones podrá darse de alta en uno de los muchos sitios que ofrecen gratuitamente este servicio. También hay de pago, con características técnicas, por supuesto, más avanzadas. Entre éstos gratuitos resultan especialmente recomendables los siguientes: www.wiki.com y www.wetpaint.com .

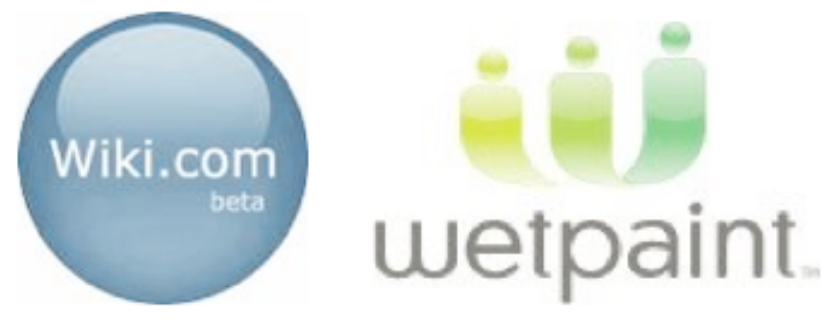

Con todo y antes de pasar a explicar la actividad didáctica en cuestión, no se puede pasar por alto lo que posiblemente sea la característica más peculiar de los sitios wiki. Ésta se refiere a que se promociona como con ninguna otra herramienta el trabajo colaborativo ya que en un mismo wiki pueden trabajar al mismo tiempo tantos alumnos y alumnas como queramos, todos ellos editando, publicando y preparando sus trabajos al mismo tiempo. Utilizando una analogía se podría pensar en un libro. Cuando se comienza un wiki se empieza a escribir en la primera hoja y según se van sumando editores, a cada uno se le asigna un capitulo de forma que entre todos y todas se va confeccionando el texto final.

Es precisamente esta característica, junto con la sencillez de uso, la que hace del wiki la herramienta educativa estrella de la web 2.0.

Teniendo todo esto presente hemos creado un Wiki, http://desampanautas.wetpaint.com dando la posibilidad de que los alumnos no se limiten solo a leer o consultar los contenidos sino que, al estar autorizados, pueden editarlos o modificarlos desde el navegador sin necesidad de tener ningún conocimiento técnico o de HTML. 


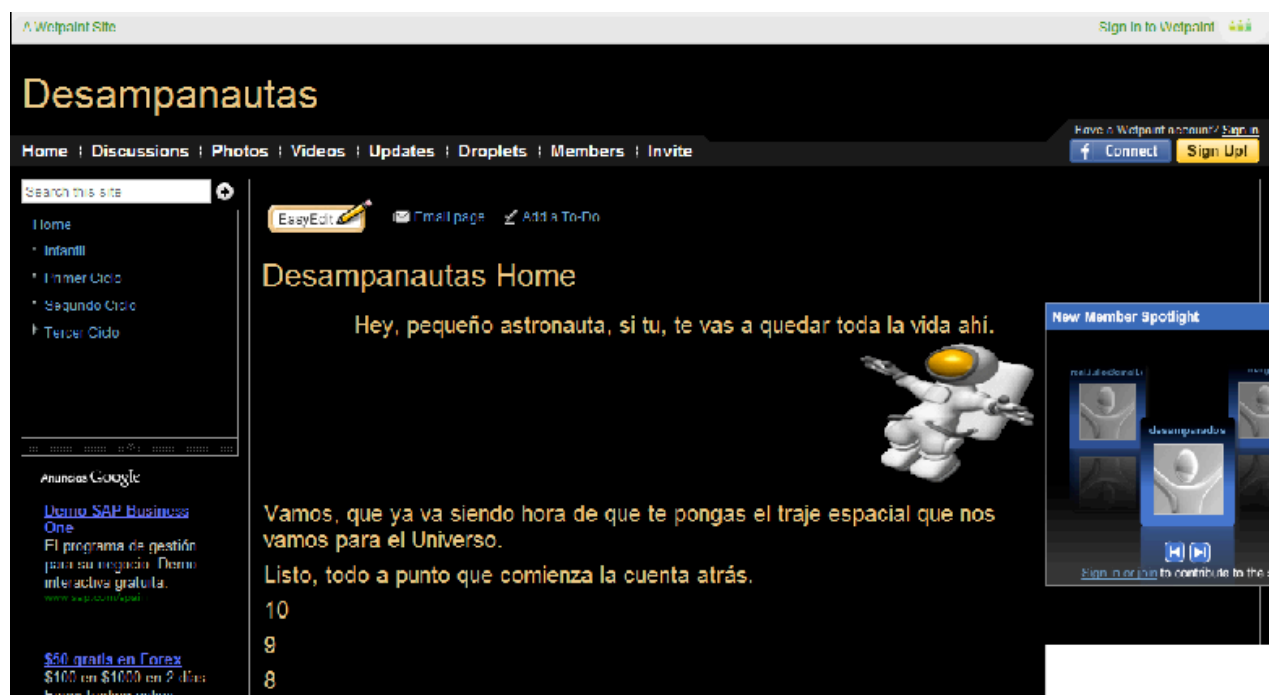

Para moverte por el Wiki lo primero que hay que haces es darse de alta, en esta ocasión sólo creamos una cuenta. Por ello, todo el alumnado accede con la misma clave pero, posteriormente cada cual edita la parte que le concierne. Es aconsejable que cada ciclo edite exclusivamente su capítulo, sin entrar en los de otros grupos, ya que de otro modo pueden generarse problemas de edición.

La edición del wiki permite que cada apartado esté compuesto de tantas "páginas-web" co-
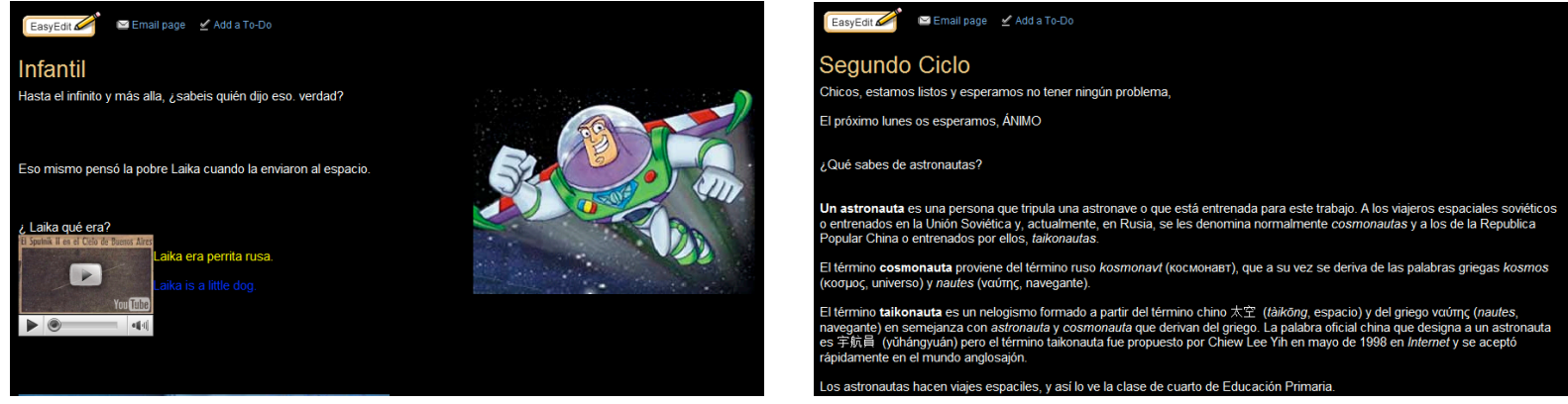

mo el grupo de trabajo decida y aprovechando esta posibilidad, se enseña y advierte al alumnado de que la publicación wiki no debe ser un único texto alojado en una única página u hoja web, sino que deben intentar escribir la información organizada en paginas-web diferentes, dedicando cada una a una subparte del trabajo total.
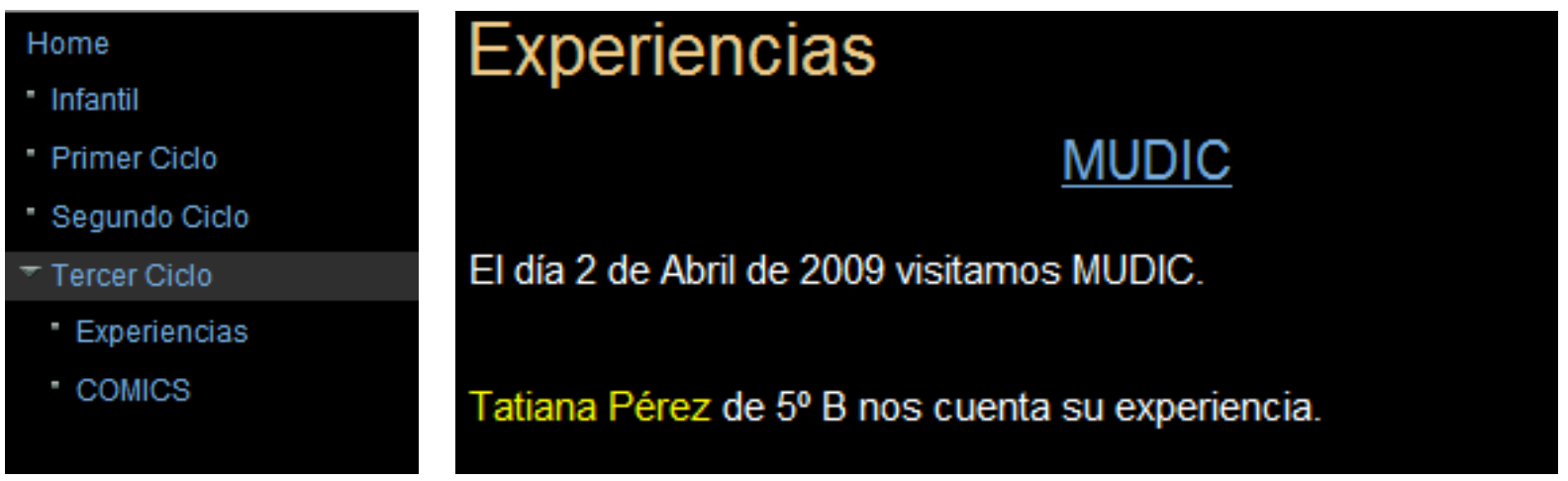

Por otra parte, resulta muy interesante y motivador para el alumnado la posibilidad de incluir fotografías y videos, que pueden buscar en sitios web o realizar ellos mismos. El alumnado, en general, suele captar rápidamente el funcionamiento del mismo sin grandes dificultades y no necesitando demasiadas explicaciones. 

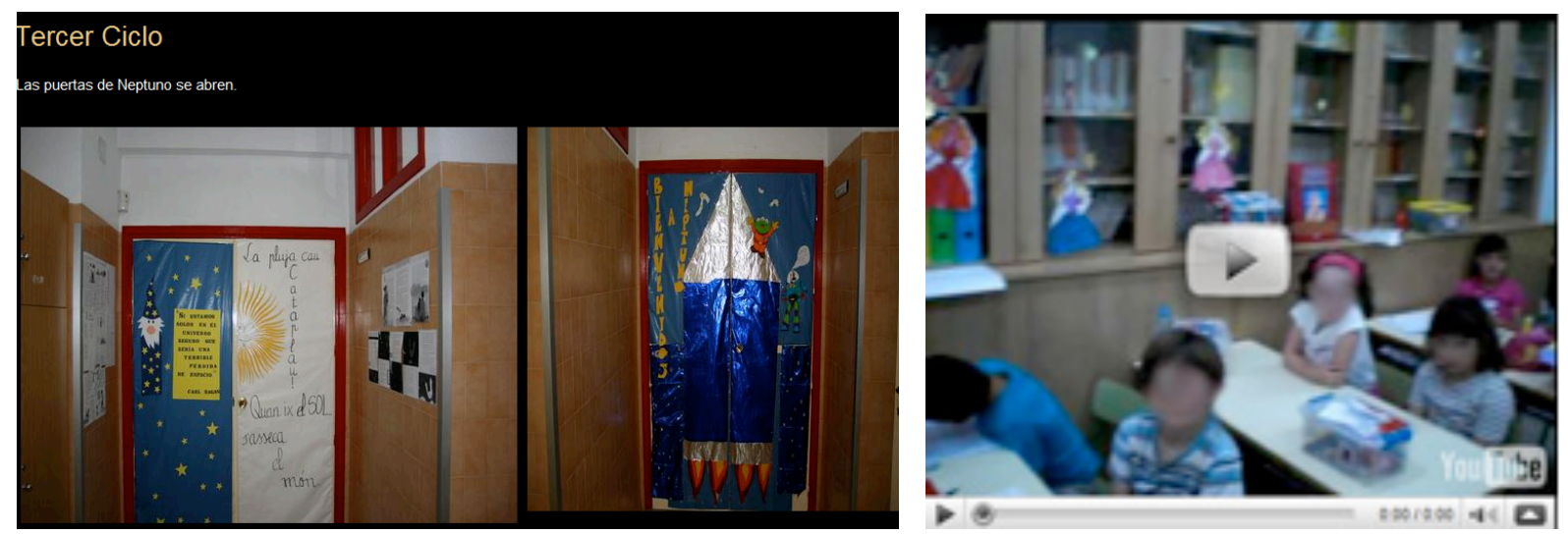

Terminado el tiempo de elaboración, se procede a la exposición pública de los wikis en el centro y cada ciclo elige a un grupo que debe presentar el trabajo realizado a la comunidad educativa: familias, alumnos y docentes.

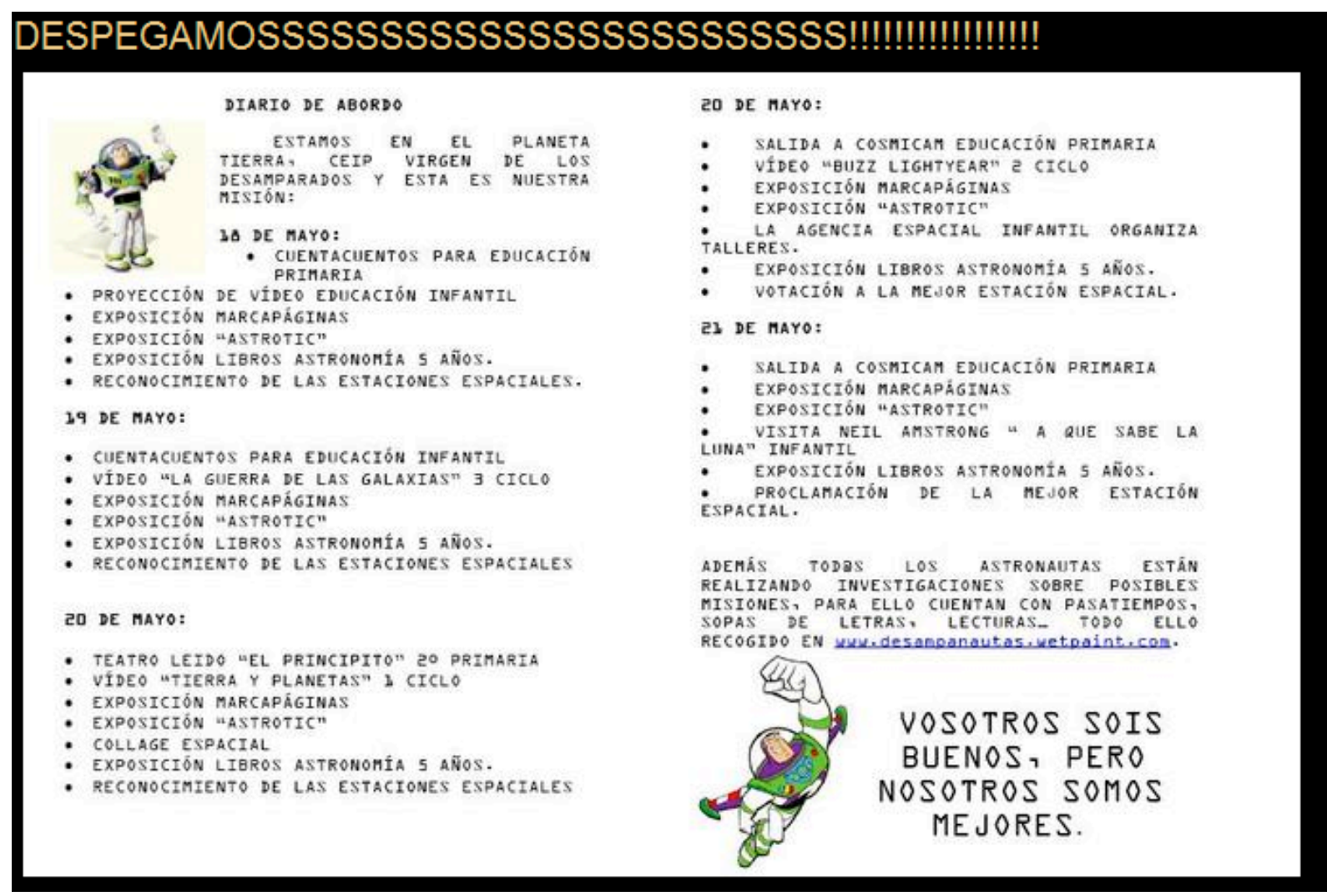

Hemos escogido la propuesta wiki de Wetpaint puesto que hace de las wikis sitios colaborativos usables para el promedio de las personas sin necesidad de conocer o manejar códigos, lenguajes de programación o programas de edición.

Otra de las razones que nos llevó a decantarnos por Wetpaint es que los espacios creados son parecidos en características a los foros de discusión, a los blogs y a las redes sociales. Es un servicio que integra la potencia y usabilidad de la Web 2.0 en las páginas colaborativas; permite de manera gratuita crear en tres sencillos pasos un completo wiki que incluye metatags, categorías, buscador, comentarios en las páginas, identificación a través de OpenID, integración de imágenes y vídeos, widgets, agregadores RSS y muchas otras funcionalidades. 
Evitar el vandalismo, es una de nuestras preocupaciones. Wetpaint permite a los moderadores borrar páginas, evitar que sean editadas, prohibir usuarios negativos y desplazar las páginas en el sitio. Esto es fundamental al trabajar con alumnos y una misma clave, como ya hemos indicado.

Ya que en los wikis se trata esencialmente de compartir información y realizar sitios en colaboración, Wetpaint ha integrado inteligentemente otra funcionalidad sencilla de utilizar que le permite enviar instantáneamente por e-mail cualquier página a cualquier persona o usuario que se desee.

Además de que Wetpaint es un servicio gratutito, te permite elegir entre una amplia gama de plantillas para personalizar el formato y apariencia de tu sitio, fundamental si queremos dar el protagonismo al alumnado.

Finalemente, la versión gratuita del servicio incluye un banner lateral de publicidad con AdSense, pero se puede pedir su eliminación en la opción de pago libre de publicidad, en este caso nosotros apostamos por la versión gratuíta. En todos los casos se dispone de plantillas prediseñadas para sitios colaborativos enfocados a grupos de estudio, clanes de juegos, grupos de amigos, equipos deportivos, clubs de lectores, entre otros.

\section{UNA EXPERIENCIA DE TRABAJO COLABORATIVO ENTRE DOCENTES EN UNA RED NING}

La experiencia se ha desarrollado en el CEIP Virgen de los Desamparados, una experiencia de uso social de las TIC entre todos los docentes del centro, con la finalidad de desarrollar un trabajo colaborativo, que contribuya a la igualdad de oportunidades entre los docentes, a mejorar la competencia profesional de manera constante y fundamentalmente que todos los docentes tengan acceso a los recursos educativos desde cualquier lugar, pudiendo desarrollar personal y autónomamente acciones tanto de enseñanza, para sus alumnos, como de aprendizaje para ellos mismos.

Desde este punto de vista Ning nos proporciona una vía para que los profesores podamos aprovechar las redes sociales en un contexto educativo, favoreciendo la actualización de los docentes en relación con el uso de las tecnologías, el cambio de estrategias didácticas y la innovación dinámica en el mismo centro. Mediante la creación de redes sociales en torno a temas académicos, los profesores podemos facilitar la comunicación entre los alumnos, fomentando interacciones personales que pueden conducir a la creación de nuevos conocimientos e inteligencia colectiva.

Una red social en Ning también es una forma fácil para que un grupo de estudiantes, o de profesores permanezcan conectados y poder intercambiar sus experiencias y sus trabajos como podemos comprobar en la que nosotros hemos creado.

Del mismo modo que un Wiki es un sitio web colaborativo cuyas páginas web pueden ser editadas por diferentes autores a través del navegador web, de tal forma que permite a los lectores o usuarios añadir, editar y modificar su contenido, aunque hayan sido creados por otros autores. 
En este sentido se ha puesto en marcha una actividad basada en el trabajo colaborativo en dos niveles, por un lado entre docentes y por otro entre alumnos, para el uso de las TIC a través de la red.

Este plan de formación contempla dos grandes fines:

- Conocer y utilizar las herramientas necesarias para integrarse en las herramientas colaborativas: wikis y redes sociales, aportando sus competencias al crecimiento de las mismas y adoptando las actitudes de respeto, participación y colaboración que posibiliten la creación de producciones colectivas.

- Mejorar la imaginación y las habilidades creativas, comunicativas, valorando las posibilidades que ofrecen las TIC en el ámbito personal, del profesorado y alumnado, y en el ámbito de la sociedad en general.

Para alcanzar los objetivos se han implementado dos sistemas diferentes:

- Una wiki que hemos denominado Desampanautas, y que hemos dejado alojada en la dirección: http://desampanautas.wetpaint.com/

- Una red social que hemos denominado Baúl de Recursos y materiales y alojado en la dirección http://enredamos.ning.com

Estas dos herramientas han de servir para su utilización tanto por parte de los profesores como de los alumnos:

- Docentes: consideramos idónea la utilización de la red Ning con objeto de:

1. Alojar materiales docentes, como son materiales multimedia, tanto creados por ellos mismos o encontrados en la red, en torno al tema consensuado, apuntes de las diferentes materia, tareas para casa... todo relacionado con la animación a la lectura.

2. Intercambiar todo tipo de archivos, permitiendo realizar las modificaciones pertinentes para su grupo de alumnos, posibilitando tanto la colaboración como la personalización de la enseñanza.

3. Instaurar un foro de discusión sobre animación a la lectura, puesto que entendemos que estamos ante un proceso de enseñanza aprendizaje vivo, dinámico y en constante actualización.

4. Plantear una agenda y calendario de eventos común para las diferentes actividades a realizar como entrega de tareas, exámenes, actuaciones, eventos especiales, resultados.,.

5. Personalizar los perfiles que tenemos en la red social más allá de la relación docente-docente. Podemos elegir nuestras amistades, exponer intereses, afinidades...

- Alumnos: se utilizará el wiki para:

1. Servir como almacén virtual de archivos y aplicaciones donde ir alojando las tareas realizadas a lo largo de todo el curso. 
2. Ser una herramienta de comunicación instantánea entre los diferentes miembros de la comunidad.

3. Proporcionar unos elementos de identificación tanto individuales como colectivos mediante la configuración de perfiles personales, y con ellos nos referimos a fondo, tipografía, fotografías, música, videos...

4. Sostener debates sobre temas propuestos por el maestro o por ellos mismos o de relevancia social, de modo que con el intercambio interactivo de ideas se vaya construyendo nuevos conocimientos.

\section{NUESTRA EXPERIENCIA}

\section{Objetivos}

1. Utilizar la Red Social como espacio de encuentro en la Comunidad Escolar

2. Utilizar el wiki como espacio colaborativo y de intercambio de experiencias entre los diferentes alumnos del centro escolar

3. Fomentar la lectura entre los alumnos del centro

4. Utilizar la Web 2.0, en concreto la Red Social y el Wiki, para desarrollar en el centro el programa "Animación a la lectura"

Contenidos

1. Redes sociales:
a. Significado y funcionamiento
b. Utilización en el entorno escolar

2. Wiki
a. Significado y funcionamiento
b. Su utilización en la escuela

3. Lectura de textos adecuados a la edad de cada alumno

Actividades

1. Regístrate en la red creada en Ning: http://enredamos.ning.com y muévete por ella para familiarizarte con los diferentes apartados.

2. Deja un comentario a cualquiera de los administradores: Antonia Cascales, Benedicto Marcos o Julio Real.

3. Sube un vídeo con contenido didáctico al espacio reservado para ello y comenta el contenido del mismo.

4. Haz un comentario en el Foro sobre el artículo "WebQuest: un modelo de aprendizaje colaborativo en red"

5. Entra en el Wiki: http://desampanautas.wetpaint.com/ y crea un grupo de discusión sobre el tema central del proyecto: "Animación a la lectura".

6. Elabora un documento final compartido con el resto de la comunidad escolar. 
Todo el trabajo desarrollado tanto por los profesores como por los alumnos ha quedado alojado en la Red Social creada http://enredamos.ning.com así como en el Wiki http://desampanautas.wetpaint.com/

\section{Metodología}

Cada grupo de alumnos debe participar en un grupo de discusión sobre el tema central del proyecto: "Animación a la lectura" creando y compartiendo, dichos comentarios, de manera que de forma instantánea y respetando la libertad de cada uno de los alumnos se elabore un documento final compartido y "compartible" con el resto de la comunidad escolar.

Para la elaboración del mismo no se precisa la revisión para que los cambios sean aceptados; debe estar abierto a toda la comunidad.

Finalmente, y tal vez lo más importante quedará expuesto como un enorme tablón de anuncios donde cualquiera pueda ir dejando sus anotaciones, enriqueciendo, lo de los otros compañeros y por supuesto creando y compartiendo todo tipo de enlaces.

El hilo conductor, o el motor lo marcaran los propios grupos de alumnos, que habrán de formular cuestiones lo suficientemente abiertas y diversas como para que el resto de compañeros puedan realizar sus aportaciones de forma colaborativa, evitando en todo momento las respuestas cerradas, que puedan generar conflictos entre los alumnos y se abran distintos horizontes dentro de la misma cuestión.

En el uso con los alumnos se ha establecido, el docente ha tenido la misión de dinamizar la red, estableciendo temas de debate, subiendo archivos, fotos, videos, ... abriendo la posibilidad que sean ellos mismos los que realicen esa labor, pero con un usuario único, para evitar que se desvíen de los objetivos iniciales.

Como cualquier actividad ha sido objeto de evaluación y calificación, basadas en la presencia y opinión en los debates creados, mediante la creación de nuevos debates, en la aportación de informaciones, videos, fotos.. en definitiva de su presencia activa en la red.

\section{RESULTADOS}

Podemos decir sin lugar a dudas que el uso de NING y wiki, ha resultado de una utilidad extraordinaria en el CEIP Virgen de los Desamparados en torno a la animación a la lectura, dado que:

- Se ha revelado como un recurso mucho más motivador y dinamizador de lo que habíamos previsto al inicio del proyecto.

- Se han abierto diferentes discusiones en las que tanto los alumnos como los docentes no se han limitado a dar su opinión, sino que han ido mas allá colgando fotos, videos, y enlaces que documentan sus exposiciones.

- El alumnado deja de ser una agente pasivo, receptor de información, para convertirse en un agente creativo al que se le facilitan medios para crear y contribuir a una publicación común, en este caso a través de un Wiki. 
- En cuanto al profesorado, ha servido para realizar un verdadero trabajo colaborativo, y como se proponía en los objetivos ha servido para personalizar la enseñanza. Ya que no sólo han realizado un trabajo en compartiendo conocimientos entre ellos, sino que al estar alojado en la red ning, han podido incluso adaptar el de sus compañeros a la realidad de su aula, y de sus alumnos.

- Tanto la enredamos como desampanautas se han convertido en grandes escaparates tanto para anunciar eventos como para narrar sus resultados. Todos hemos estado pendientes de las novedades, tareas, eventos y enlaces sobre animación a la lectura para subirlo a nuestra red.

\section{CONCLUSIÓN}

Como conclusión, entendemos que si bien no es nueva la observación de que la inclusión de herramientas tecnológicas novedosas pueden ser una ayuda para mejorar la motivación del alumnado hacia la actividad en el aula, sí que resulta atractivo para el alumnado cambiar los roles, pasar de meros observadores a productores con el aliciente de la exposición publica proporcionadas por las wikis.

Debemos destacar la motivación, dinamismo y continuidad obtenidas tanto por el profesorado como por los alumnos, que nos ha llevado a integrar otro espacio común de trabajo en el centro, las redes sociales y wikis. Siendo precisamente la posibilidad de crear y de contribuir a una publicación común, tanto para los docentes con enredamos como para el alumnado con desampanautas, el aspecto más sobresaliente de esta propuesta didáctica.

\section{BIBLIOGRAFÍA}

BARABASI, A. (2003). Linked: How Everything Is Connected to Everything Else and What It Means. London: Plume.

BARNES, J. A.(1954). Class and committes in a Norwegian Island Parish, en Human Relations, vol. 7, 1954, pp. 39-58.

BOYD, D. M. (2007). Social Network Sites: Public, Private, or What?. The Knowledge Tree.

http://kt.flexiblelearning.net.au/tkt2007/edition-13/social-network-sites-public-private-orwhat/.

BOYD, D. M. (2008). The Economist Debate on Social "Networking". apophenia :: making connections where none previously existed. Weblog.

http://www.zephoria.org/thoughts/archives/2008/01/15/the_economist_d.html.

BOYD, D. M., \& ELLISON, N. B. (2007). Social Network Sites: Definition, History, and Scholarship. Journal of Computer-Mediated Communication, 13(1). http://jcmc.indiana.edu/vol13/issue1/boyd.ellison.html.

CABELLO, J. L. (2008). Comunidades virtuales de práctica. http://camarotic.es/?p=9. 
DÍAZ. M. Redes sociales en Internet: aplicación FOAF (Friend-of-a-Friend) http://scielo.sld.cu/pdf/aci/v15n6/aci09607.pdf [Fecha de consulta 02/09/2009]

GANNON-LEARY, P. M., \& FONTAINHA, E. (2007). Communities of Practice and virtual learning communities: benefits, barriers and success factors. elearning papers, 5. http://www.elearningeuropa.info/out/?doc_id=12522\&rsr_id=13563.

LAVE, J., \& WENGER, E. (1991). Situated learning : legitimate peripheral participation. Cambridge [England];New York: Cambridge University Press.

PRENDES, M. P. \& SOLANO, I. M. (2008). EDUTEC en la red. Comunidades virtuales para la colaboración de profesionales. EDUTEC, Revista Electrónica de Tecnología Educativa. Núm. 25/Marzo 2008. [Fecha de consulta: 8/06/08].

http://edutec.rediris.es/.../Edutec25_Edutec_en_la_red_cominades_virtuales_colaboracion. html

RODRÍGUEZ DÍAZ J. A. (2005): Análisis estructural y de redes. Centro de Investigaciones Sociológicas (Cuadernos Metodológicos) Madrid

Wikipedia, Seis grados de separación. http://es.wikipedia.org/wiki/Seis_grados_de_separaci\%C3\%B3n [Fecha de consulta 02/09/2009]

ISFTIC. Presentaciones on-line y Redes Sociales Educativas. http://observatorio.cnice.mec.es/modules.php?op=modload\&name=News\&file=article\&sid $=554$ [Fecha de consulta 02/09/2009]

\section{Para citar este artículo:}

CASCALES, A.; REAL, J. J. \& MARCOS, B. (2011). Las redes sociales en internet. Edutec-e, Revista Electrónica de Tecnología Educativa, 38. Recuperado el dd/mm/aa desde http://edutec.rediris.es/Revelec2/Revelec38/redes_sociales_internet.html 